\title{
Migraine in women: the role of hormones and their impact on vascular diseases
}

\author{
Simona Sacco $\cdot$ Silvia Ricci $\cdot$ Diana Degan • \\ Antonio Carolei
}

Received: 26 January 2012/ Accepted: 8 February 2012/ Published online: 26 February 2012

(C) The Author(s) 2012. This article is published with open access at Springerlink.com

\begin{abstract}
Migraine is a predominantly female disorder. Menarche, menstruation, pregnancy, and menopause, and also the use of hormonal contraceptives and hormone replacement treatment may influence migraine occurrence. Migraine usually starts after menarche, occurs more frequently in the days just before or during menstruation, and ameliorates during pregnancy and menopause. Those variations are mediated by fluctuation of estrogen levels through their influence on cellular excitability or cerebral vasculature. Moreover, administration of exogenous hormones may cause worsening of migraine as may expose migrainous women to an increased risk of vascular disease. In fact, migraine with aura represents a risk factor for stroke, cardiac disease, and vascular mortality. Studies have shown that administration of combined oral contraceptives to migraineurs may further increase the risk for ischemic stroke. Consequently, in women suffering from migraine with aura caution should be deserved when prescribing combined oral contraceptives.
\end{abstract}

Keywords Migraine - Hormones - Contraceptive · Pregnancy $\cdot$ Menopause

Electronic supplementary material The online version of this article (doi:10.1007/s10194-012-0424-y) contains supplementary material, which is available to authorized users.

S. Sacco $(\bowtie) \cdot$ S. Ricci $\cdot$ D. Degan · A. Carolei

Department of Neurology and Regional Referral Center for

Headache Disorders, University of L'Aquila, Piazzale Salvatore

Tommasi, 1, 67100 L'Aquila, Italy

e-mail: simona.sacco@cc.univaq.it; simona.sacco@yahoo.com

\section{Introduction}

Migraine is a predominantly female disorder. Women, compared with men, have a 1-year migraine prevalence nearly threefold higher (17 vs. $6 \%$ ) and lifetime incidence more than twofold higher (43 vs. 18\%) [1, 2]. Moreover, menarche, menstruation, pregnancy, and menopause as use of oral contraceptives and of hormone replacement treatment (HRT) may influence migraine occurrence. Until puberty, migraine affects both sexes equally [3]. After the menarche there is an increasing prevalence of migraine in women $[4,5]$. The mechanism for the gender difference in migraine is not clear even if endogenous sex steroids are considered to play a relevant role.

\section{Migraine during women's life}

The woman's reproductive cycle is regulated by the hypothalamic-hypophyseal-ovarian axis through the release of estrogen and progesterone. Variations in the levels of these hormones and of their feedback control regulate the menstrual cycle, pregnancy, puerperium, and menopause (Fig. 1).

A normal menstrual cycle lasts about 28 days and consists of two phases: the follicular or the proliferative phase and the luteal or ovulatory phase. The first day of menstruation is considered the start of follicular phase and bleeding occurs after estrogen and progesterone levels decrease at the end of the previous cycle. At this time, the pituitary follicular stimulating hormone (FSH) level increases slightly, stimulating the development of several ovarian follicles. Each follicle contains an oocyte; only one follicle proceeds through ovulation producing increased levels of estrogens, which result in a drop of the FSH production, preventing the additional development of 
Fig. 1 Hormonal changes and incidence of migraine without aura in women

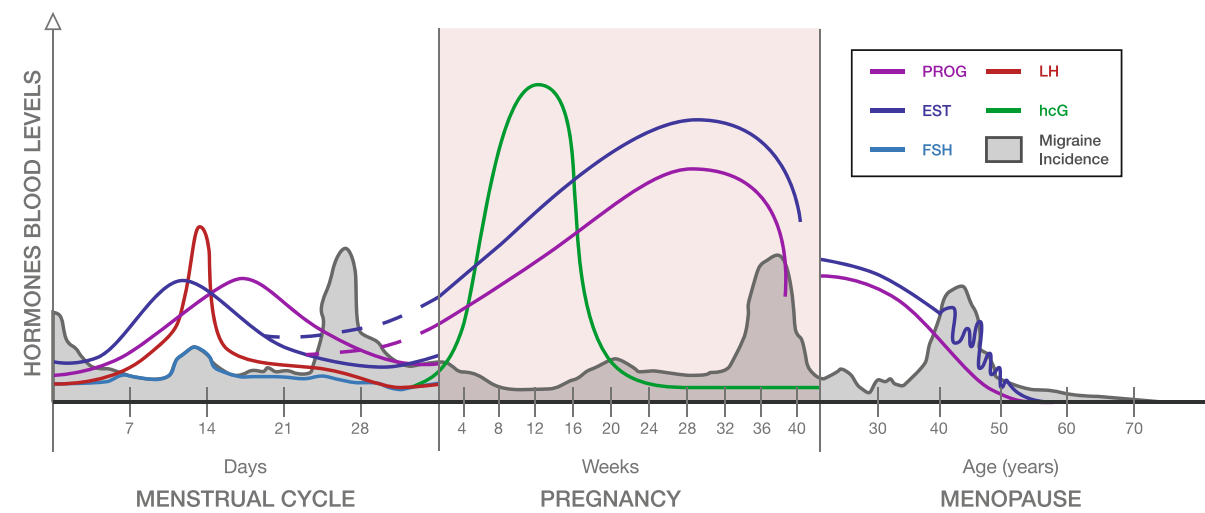

follicles, and in the stimulation of the hypophysis to release the luteinizing hormone (LH). Progesterone remains low during the follicular phase except for a small rise just prior to ovulation. At the time of ovulation, a mature follicle ruptures in response to a surge of $\mathrm{LH}$, releasing a mature oocyte. The luteal phase starts just after ovulation and during this phase the follicle, denominated corpus luteum, secretes progesterone and estrogen, which stimulate the endometrium to prepare a thick layer of blood vessels for possible fertilization. If no pregnancy occurs, the corpus luteum persists for about 14 days and then degenerates with a fall in blood estrogen and progesterone levels and a shedding of the top layers of endometrium for the beginning of a new menstrual cycle.

When pregnancy occurs, the trophoblast releases the human chorionic gonadotropin (hCG) which allows the corpus luteum to continue to produce estrogen and progesterone until the formation of the placenta. The placenta, from that point on, produces the majority of estrogen and progesterone necessary for the pregnancy. Serum levels of estradiol and progesterone begin to rise in the mother during the 6th to 8th week of pregnancy and continue to gradually increase to their highest levels during the third trimester; serum estradiol levels during the third trimester of pregnancy are 30-40 times higher and progesterone levels are 20 times higher than their peak levels during natural menstrual cycles. The hormonal levels drop sharply during the puerperium that is defined as the time from delivery of the placenta through the first few weeks after the delivery (usually 6 weeks) and represents the phase in which the woman's body returns back to prepregnancy condition.

The transition from the reproductive to the non-reproductive phase occurs over a period of years and is the result of a reduction in female hormonal production by the ovaries. Although the perimenopausal period is characterized by considerable fluctuations of estrogen and progesterone levels, higher than during the normal phases of menstrual cycle in the fertile period, the menopause is characterized by hormonal stability due to decline of estrogen and progesterone production by the ovaries. The average age of menopause is 51 years, within an age range of 40-60 years [6].

Menstrual cycle

Throughout the reproductive years, menstruation is one of the most significant events related to the occurrence of migraine attacks [7, 8] (Fig. 1). Compared with all other phases of the menstrual cycle, incidence of migraine without aura (MwA) is greatest during a 5-day window that starts 2 days before the onset of menstruation and continues through the first 3 days of menstruation [9-12]. The International Classification of Headache Disorders, II edition (ICHD-II) identifies in the Appendix: (a) menstrually related migraine, which is MwA that regularly occurs on or between days -2 to +3 of menstruation, with additional attacks of migraine with aura (MA) or MwA at other times of the cycle; (b) pure menstrual migraine (MM), which is MwA that occurs only on or between days -2 to +3 , with no attacks at any other time of the cycle [13] (Table 1). Pure MM is uncommon with respect to menstrually related migraine. Fewer than 10-20\% of women report migraine exclusively with menstruation and at no other time of the month [9, 14-17]. Generally, the term MM includes both types of those attacks. MM attacks occur almost invariably without aura even in MA patients [7, 18, 19]. According to the majority of the available studies, compared with migraine at other times of the cycle, menstrual attacks last longer, are more severe, more likely to relapse, less responsive to treatment, and associated with greater disability [11, 12, 18, 20-24]. According to some studies, MM attacks are accompanied by nausea and vomiting more than non-menstrual attacks [18, 19] although this finding is not unanimously shared by all the studies [12, 22, 24, 25]. Correlations have been identified between premenstrual syndrome and MM [26, 27]. The association of migraine with ovulation is controversial but generally not supported despite some women may report attacks during this phase 
Table 1 Diagnostic criteria according to the International Classification of Headache Disorders, II edition, for pure menstrual migraine without aura and menstrually related migraine without aura

A1.1.1 Pure menstrual migraine without aura

Diagnostic criteria

A. Attacks, in a menstruating woman, fulfilling criteria for 1.1. Migraine without aura

B. Attacks occur exclusively on day $1 \pm 2$ (i.e., days -2 to +3$)^{\mathrm{a}}$ of menstruation ${ }^{\mathrm{b}}$ in at least two out of three menstrual cycles at no other times of the cycle

A1.1.2 Menstrually related migraine without aura

Diagnostic criteria

A. Attacks, in a menstruating woman, fulfilling criteria for 1.1. Migraine without aura

B. Attacks occur on day $1 \pm 2$ (i.e., days -2 to +3$)^{\mathrm{a}}$ of menstruation $^{\mathrm{b}}$ in at least two out of three menstrual cycles and additionally at other times of the cycle

a The first day of menstruation is day 1 and the preceding day is -1 ; there is no day 0

${ }^{b}$ For the purposes of this classification, menstruation is considered to be endometrial bleeding resulting from either normal menstrual cycle or from the withdrawal of exogenous progestogens, as in the case of combined oral contraceptives and cyclical hormone replacement therapy

[19]. While MwA is clearly associated with menstruation, MA is generally unrelated to them [4]. Even in patients with aura accompanying their migraine attacks during the remaining of the month, the MM attacks are without aura $[10,12]$.

Pregnancy and puerperium

Most epidemiological studies have demonstrated that the majority of women suffering from migraine note remarkable and increasing improvement of their attacks during pregnancy, from the first to the third trimester $[7,15,28-$ 30] (Fig. 1). Improvement is more likely in women with a history of MM [7, 30, 31]. If migraine does not improve by the end of the first trimester, it is likely to continue throughout the pregnancy [32]. In fact, a small number of pregnant women experience a worsening of their migraine [7, 15], while a few others may even develop de novo migraine symptoms [33]. The worsening usually occurs during the first trimester [34] and involves women suffering from MA rather than from MwA; also de novo migraines during pregnancy mostly consist of MA [14, 35].

Nearly all women report the return of migraine attacks after delivery [15, 32]. Factors accelerating the return of migraine attacks in the postpartum include bottle-feeding and age of 30 years or less [30].

Women suffering from migraine are also at higher risk of developing gestational hypertension, preeclampsia, or vascular complications related to pregnancy including ischemic stroke and other vascular events in the peripartum period $[36,37]$. The risk is particularly evident in those women not showing remission or amelioration of migraine attacks. Even neonatal outcomes may be affected by the persistence of migraine $[38,39]$. For all the above reported reasons, migraine should be considered a potential risk factor in obstetric care.
Menopause

During the transition to menopause some women may experience a worsening of the migraine attacks [40], but usually, postmenopause is also associated with respite [41] (Fig. 1). The type of menopause has a substantial effect on migraine: natural menopause is associated with a lower prevalence of migraine compared to surgical menopause $[15,40,42]$. The longer is the time interval from menopause onset, the greatest is the association with improvement $[41,43]$. Whether migraine is associated with other menopause symptoms is unclear since data from available studies are conflicting [43, 44]. In contrast to the effects of menopause on MwA, prevalence of MA does not improve with menopause [43].

\section{Contraceptives}

Several forms of hormonal contraceptives are available: combination oral contraceptives (COCs), progestin-only contraceptives, 91-day combination oral contraceptives, combination patch contraceptives, and contraceptive vaginal rings. Start of hormonal contraceptives may have different effects on migraine (Table 2). The best-studied contraceptives in relation to migraine are COCs. There is a well-documented association between COCs and migraine [45]. They may induce a de novo migraine in women without a previous history of the disease, worsen a previous existing migraine, or change the pattern of a previous existing migraine (from MwA toward MA); in some cases no changes occur with COCs use [14, 15, 46]. Migraine worsening in frequency or severity has been reported in $18-50 \%$ of cases, migraine improvement has been reported in $3-35 \%$, and no change in $39-65 \%$ of cases [47]. In COCs users in which migraine persists, attacks are more likely to occur during the pill-free week [47-51]. The 
Table 2 Diagnostic criteria according to the International Classification of Headache Disorders, II edition, for exogenous hormone-induced headache and estrogen-withdrawal headache

8.3.1 Exogenous hormone-induced headache

Diagnostic criteria

A. Headache or migraine fulfilling criteria $\mathrm{C}$ and $\mathrm{D}$

B. Regular use of exogenous hormones

C. Headache or migraine develops or markedly worsens within 3 months commencing exogenous hormones

D. Headache or migraine resolves or reverts to its previous pattern within 3 months after total discontinuation of exogenous hormones

Comments: regular use of exogenous hormones, typically for contraception or hormone replacement therapy, can be associated with increase in frequency or new development of headache or migraine. When a woman experiences headache or migraine associated with exogenous estrogen-withdrawal, both codes 8.3.1 exogenous hormone-induced headache and 8.4.3 estrogen withdrawal headache should be used

8.4.3 Estrogen-withdrawal headache

Diagnostic criteria

A. Headache or migraine fulfilling criteria $\mathrm{C}$ and $\mathrm{D}$

B. Daily use of exogenous estrogen for $\geq 3$ weeks, which is interrupted

C. Headache or migraine develops within 5 days after last use of estrogen

D. Headache or migraine resolves within 3 days

Comments: estrogen-withdrawal following cessation of a course of exogenous estrogens (such as during the pill-free interval of combined oral contraceptives or following a course of replacement or supplementary estrogen) can induce headache and/or migraine

addition of supplemental estradiol during the perimenstrual period, continuing the administration of hormonally active pills, or extended transdermal application is associated with an overall reduction in migraine severity and frequency [49, 51-53]. Patients suffering from pure MM are particularly sensible to COCs use and reduction of the pill-free period is associated with reduced migraine burden [54]. The use of COCs worsens to a greater extent in MA than MwA [7]. Moreover, patients may develop aura symptoms for the first time in association with the initiation of therapy [55]. The use of progesterone-only contraceptives may reduce the number of attacks in MA and may ameliorate aura symptoms in women in whom MA onset was related to previous COCs treatment [56].

\section{Hormone replacement treatment}

HRT has a variable effect on migraine (Table 2). Most women with headache report improvement or complete remission of their headache, associated with HRT use; a minority of women report no change or worsening of the headache [46]. Specifically, HRT is associated with an increased risk of migraine headache [57]. There are no significant differences in the risk of migraine headache in users of cyclic versus continuous doses of estrogens and no dose-response relationship has been reported [57]. HRT may trigger migraine attacks in women without a past history of migraine or may also cause the reappearance of migraine in those women who had the disorder before menopause [57, 58]. Worsening of migraine in menopause may be a factor in predicting worsening of migraine with HRT [59]. It is worth mentioning that in some cases HRT is recommended for perimenopausal women with migraine $[60,61]$. Further, studies suggest that non-oral routes of delivery of estrogen are more likely to improve migraine than oral estrogens [62] probably because of lower fluctuations in estrogens levels.

HRT may have adverse effects on MA. It may worsen a preexisting MA or it may induce MA in women without history of the disease [63]. In those cases, withdrawal of estrogens and additional migraine prophylaxis lead to improvement or complete cessation of migraine [63]. Other studies reported also that MA may resolve with either a reduction in estrogen dose or change in route of delivery of estrogen (switch from oral to transdermal administration) [62].

\section{Mechanisms linking sex hormones and migraine}

The observation that migraine is predominantly a female disorder and that several reproductive milestones correlate with a change in migraine frequency or type, implicates sex hormones in the pathogenesis of migraine. Sex steroids differentially influence MA and MwA.

The pathogenesis of $\mathrm{MM}$ as of all changes in migraine related to hormones has not been fully characterized but appears to be related to estrogen withdrawal [19, 64]. The original study that reported the potential influence of estrogen withdrawal on headache was done over 30 years ago [65]. Women were selected based on their susceptibility to have MM; female migraineurs who were given estradiol had a delay in their migraine attacks until the level of estradiol dropped to pretreatment levels. A second study by the same author showed that treatment with 
progesterone resulted in a delay in bleeding and no change in the headache pattern [65]. These results served to postulate that the drop in estrogen was the cause for migraine in vulnerable women. Additional clinical evidence supports the role of estrogen withdrawal as a trigger for MwA. Several biological conditions associated with a fall in estrogens are repeatedly shown to be associated with a worsening of MwA: immediately before menstruation, during the pill-free period in women using $\mathrm{COC}$ or oral HRT, in hysterectomized women with bilateral oophorectomy, and delivery. Sudden estrogen withdrawal was associated with migraine also in women who received gonadotropin-releasing hormone as part of in vitro fertilization [66]. Continuous COCs use decreased headache dramatically [67]. On the opposite, high estrogen levels as occurring in the second and third trimester of pregnancy or their complete withdrawal such as in menopause, protect against MwA. Perimenopause, a time when the levels of circulating sex hormones fluctuate irregularly, is often associated with worsening or change in migraine patterns. At variance, conditions associated with high estrogen levels may lead to the development of MA. This occurs in women starting COCs, HRT, and during pregnancy. Reasons that may explain why some women are prone to migraine onset or worsening in relation to hormonal changes while others are not, are currently unclear. Differences may be related to the ability to metabolize estrogens or to polymorphism in genes encoding for sex hormones, their receptors, or metabolites of the hormonal pathways. As an example, a single nucleotide polymorphism in the estrogen receptor 1 gene G594A exon 8 [68] and the presence of a polymorphism of the progesterone receptor positively correlated with the incidence of migraine attacks [69].

Estrogens may interfere with cellular excitability or cerebral vessels. Ovarian steroids cross the blood-brain barrier by passive diffusion, with brain levels mirroring blood levels [70] and are also produced within the central nervous system [71]. Estrogen and progesterone can influence the pain-processing networks and the endothelium involved in the pathophysiology of migraine. Interrelationships between estrogens and brain neurotransmitters have been confirmed, including serotonin, norepinephrine, dopamine, and endorphins [42, 72]. In particular, estrogen has potent effects on the serotonergic system, increasing serotonergic tone. Prostaglandins have also been implicated in MM [73]. In particular, entry of prostaglandins into the systemic circulation can trigger throbbing headache, nausea, and vomiting [74]. Estrogen facilitates the glutaminergic system, potentially enhancing neural excitability. This effect is modulated by progesterone, which appears to activate GABAergic systems, suppressing neuronal reactivity [75]. Induction of cortical spreading depression (CSD) which is involved in the pathophysiology of migraine, depends on glutamatergic transmission [76, 77]. In addition, peak estrogen levels are associated with a significant decrease in serum $\mathrm{Mg}^{++}$levels that could facilitate $N$-MethylD-Aspartate (NMDA) channel opening [78]. Changing central opioid tonus has been proposed as another mechanism that may induce migraine around the time of menstruation [79]. In contrast to women without MM, patients with MM exhibit poor response to $\mathrm{LH}$ after being injected with the opiate antagonist naloxone during the luteal phase of the menstrual cycle [80]. In an analysis of opioid tonus in women with MM, plasma $\beta$-endorphin and cortisol responses were impaired during the premenstrual period [72], indicating that premenstrual opioid hyposensitivity may contribute to the risk of MM. Estrogens may be involved in migraine pathophysiology also affecting the vasculature through stimulation of nitric oxide (NO) release [75, 81]. The estrogen receptor $\alpha$ increases NO synthase activity in the endothelium [82]. Women with a history of MM, with respect to women with migraine unrelated to the menstrual cycle or without migraine exhibit a heightened activation of the NO and L-arginine pathway and an increase in NO, especially during the luteal phase [83].

Estrogens may enhance susceptibility to MA by increasing cortical excitability. Studies of effects of estrogen on seizure threshold support this hypothesis. Estradiol enhances seizure susceptibility in females by decreasing the after-discharge threshold and facilitating kindling [84]. In patients with catamenial epilepsy, transcranial magnetic stimulation of motor cortex demonstrated a shorter cortical silent phase reflecting decreased inhibition during the luteal phase and during menstruation [85].

\section{Migraine, hormones and the risk of vascular diseases}

\section{Migraine as a risk factor for vascular diseases}

The higher-than-expected incidence of vascular disease (VD) reported in migraineurs suggests that migraine may, in some cases, be a dangerous condition rather than just a troublesome, but innocent, disorder [86-89] (Table 3). Available data support an increased risk of ischemic and hemorrhagic stroke, cardiac disease, retinal vasculopathy, and mortality in migraineurs suffering from MA [88, 89]. Several alternative conditions including thrombophilia, patent foramen ovale, arterial dissection, and autoimmunity have been advocated in the attempt to explain the high burden of VD in migraine but none of them fully explains the risk $[88,89]$. This increased risk is not linked to any of the conventional vascular mechanisms underlying the above conditions, but rather to a specific systemic vascular vulnerability that is associated with migraine [90]. Whereas, there exists a huge body of evidence on the association between VD and migraine in women, data on 
Table 3 Migraine and the risk of vascular disease

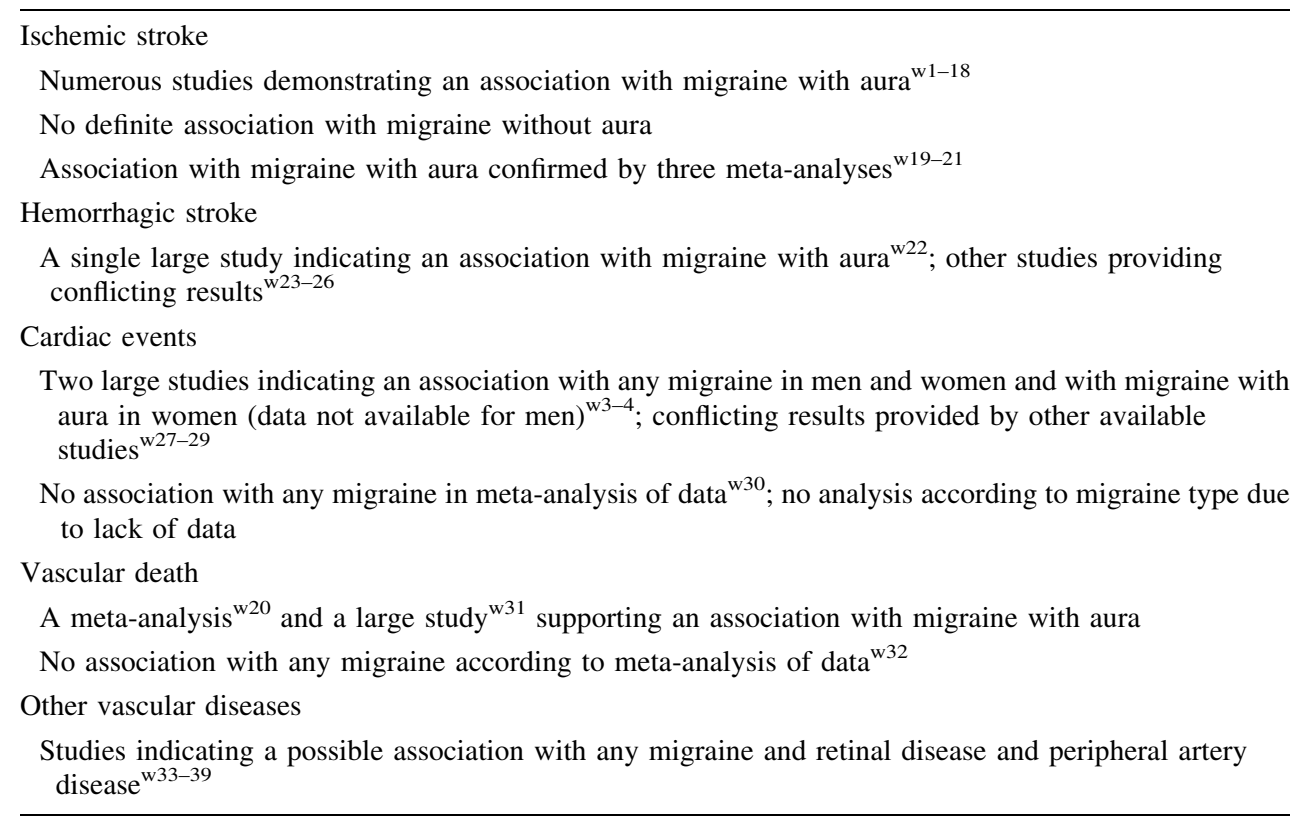

migraine in men are scarce and lacking in detail, particularly as regards migraine type. Since no direct estimates of the risk in men versus women are available, it is impossible to establish whether the risk is higher in one of the two sexes. Bearing these limitations in mind, the available evidence suggests a definite increase in the risk of vascular events in the cerebral and cardiac districts in women suffering from MA while in men the same evidence is not definite. A recent meta-analysis showed an increased risk of ischemic stroke in women with any migraine versus women with no migraine, but not in men with any migraine versus no migraine [91]. According to incidence curves for ischemic stroke in the Women's Health Study (WHS) and men in the Physicians' Health Study (PHS), the association between migraine and ischemic stroke becomes more apparent over time in women, whereas in men it diminishes $[92,93]$. This pattern suggests the involvement of different concurrent mechanisms according to gender. In both the WHS and the PHS, the presence of any migraine was associated with a greater risk of major vascular events, mostly due to an increase in myocardial infarction (not in ischemic stroke) $[92,93]$. Women, but not men, were also found to be at increased risk of coronary revascularization, angina, and death from VD. In the American Migraine Prevalence and Prevention study, in both sexes stroke was more likely to occur in subjects with MA than in those with MwA. The same study reported an increased risk of vascular events in both men and women affected by any migraine, MA, and MwA [94]. Although, as mentioned, direct comparisons between men and women are lacking, the odds ratios were higher in men than in women, while confidence intervals were mostly overlapping. Data on mortality are conflicting. In the WHS, women affected by
MA showed an increased risk of death from VD, while in the PHS, men suffering from any migraine did not present an increased risk of death from VD [92, 93]. Conversely, in the Reykjavik study, mortality from VD was marginally greater in men than in women affected by any migraine and by MwA [95]. A more recent meta-analysis assessed the relationship between migraine and mortality in ten cohort studies, in four of which MA and MwA were investigated separately [96]. The analyzed studies showed medium-tohigh heterogeneity. The results indicated that the presence of any migraine did not alter the risk of all-cause, vascular, or coronary artery disease mortality. They also indicated that MA, but not MwA, increased the risk of VD and coronary artery disease mortality.

\section{Vascular effects of estrogens}

The disparities in VD between premenopausal women and men of the same age suggest that endogenous sex hormones have a major vascular action and a protective effect from VD in women. Estrogens through receptor-operated mechanisms regulate peripheral arterial function, lipid metabolism, inflammation, oxidative stress, fibrinolysis, and thrombosis [97-99]. Estrogen receptors are expressed in myocardial cells, vascular smooth muscle cells, and endothelial cells in both humans and animals [99]. Antiatherogenic effects of estrogens are partially due to inhibition of vascular smooth muscle cells growth, proliferation, and contractility and may also affect endothelial cell regeneration and angiogenesis [100-103]. Several observations suggest that estrogens modulate endothelium-dependent relaxation by increasing vascular NO release. Basal vascular release of NO is generally 
higher in vessels derived from females than in those from males, and this difference is due to female sex hormones [104]. Both pregnancy and estradiol treatment increase endothelial NO synthase (eNOS) activity [105]; estradiol also increases eNOS activity and NO production in cultured endothelial cells [106, 107]. Moreover, estrogens reduce mitochondrial generation of reactive oxygen species [98]. In the absence of estrogen, endothelium-dependent release of $\mathrm{NO}$ is reduced, and the ability of estrogen to increase this response depends on the time-period an individual is without estrogen exposure [98]. However, estrogen signaling pathways are altered in older women, particularly in those with subclinical vascular disease, in a manner that converts vasoprotective effects to vasculotoxic effects. In fact, in premenopausal women, atherosclerotic coronary arteries express considerably less estrogen receptors than do normal arteries [108], suggesting that atherosclerosis is associated with diminished estrogen receptors expression, and that the antiatherogenic effects of estradiol are in part mediated through cardiovascular estrogen receptors [102, 108].

In cardiovascular tissues, as in others, estrogen can induce progesteron receptor (PR) expression [109]. Progestins inhibit estradiol-induced endothelium-mediated vascular relaxation [110], increase LDL and decrease HDL cholesterol levels [99], and high doses of progesterone also nullify the ability of estradiol to reduce intimal plaque size and cellular proliferation in a rabbit model of experimental atherosclerosis [111, 112]. Progesterone stimulates thrombospondin-1 expression by both endothelial cells and vascular smooth muscle cells, which potentially inhibits endothelial cell adhesion, migration, proliferation, and angiogenesis [113]. In contrast, micromolar concentrations of progesterone have been reported to induce endotheliumdependent relaxation of rabbit coronary artery [114] and to inhibit the induction of platelet calcium responses [115].

\section{Hormonal treatments and vascular diseases}

While endogenous female hormones have a protective role with respect to VDs, exogenous hormones have, in most cases, neutral or deleterious effects. Many studies have suggested an increased risk of venous and arterial complications associated with COCs, primarily pills containing high doses of ethinylestradiol, raising concerns about their use. The risks of venous thromboembolism have been well established [116] while the risks of arterial diseases are more controversial. The risk of arterial disease is related to the dose of ethinylestradiol in the formulation. Evidences show that high-dose COCs (containing $\geq 50 \mu \mathrm{g}$ of ethinylestradiol) are associated with an elevated risk of ischemic stroke while low-dose formulations $(<50 \mu \mathrm{g}$ of ethinylestradiol) are associated with a lower increase in the risk of stroke; data are not as clear regarding the risk of stroke associated with $20 \mu \mathrm{g}$ versus 30 or $35 \mu \mathrm{g}$ formulations [117]. Similarly, there are conflicting data regarding whether type of progesterone influences stroke risk in lowestrogen formulations. Second-generation progestogens (e.g., ethynodiol acetate, levonorgestrel, and norethisterone) are associated with a greater increase in the risk of myocardial infarction and ischemic stroke than third-generation progestogens (desogestrel, gestodene, norgestimate). For most women, COCs are a safe and highly effective method of contraception with added non-contraceptive health benefits. High-dose COCs, particularly those containing first-generation progestogens, are no longer recommended for routine use and low-dose formulations containing either second- or third-generation progestogens should be used, where possible. Users at a greater risk for venous or arterial vascular diseases include women over 35 years of age, heavy smokers, as women with high or abnormal blood lipids, with severe diabetes arterial damage, with consistently elevated blood pressure values, who are obese, or who suffer from migraine [55, 118]. Many studies have reported increased odds of stroke in migraineurs who use COCs [119-125]. According to a metaanalysis of available data, women with a history of migraine who use COCs are two to four times as likely to have an ischemic stroke as nonusers with history of migraine [126]. Reported odds ratios for ischemic stroke in migraineurs using combination contraception range from 2 to nearly 14, compared with nonusers (Table 4). A recent systematic review and meta-analysis of 9 studies found that the pooled relative risk of ischemic stroke in women aged less than 45 years with any migraine was 3.6 , and the risk of ischemic stroke was further increased to 7.2 among women currently using COCs [91]. Coexistence of risk factors such as, COCs use and smoking has more than multiplicative effects on the odds ratios for ischemic stroke associated with migraine; the reported odds ratio of 34 for ischemic stroke among migraineurs women who use oral contraceptives and smoke is a matter of considerable concern [119]. At variance, high blood pressure showed a more linear relationship with the risk of ischemic stroke in migraineurs [119]. No studies had enough power to examine the risk of stroke by COC use and type of migraine (with or without aura) simultaneously. However, available evidences may suggest that COCs use may exacerbate the underlying vascular pathological condition of migraineurs.

There have been many studies and clinical trials conducted in an attempt to address whether or not there is an increased incidence of VD among postmenopausal women on HRTs. The results of the Women Health Initiative study on HRTs and VD concluded that HRTs have no protective effect on the cardiovascular system. It has been suggested that HRTs may even promote the development of vascular events [127-130]. Transdermal estrogen has been 
Table 4 Risk of ischemic stroke in women by migraine status and COCs use

\begin{tabular}{|c|c|c|c|c|c|}
\hline & \multirow[t]{2}{*}{ Type of contraceptive } & \multicolumn{4}{|c|}{ Risk of ischemic stroke OR; 95\% CI } \\
\hline & & $\begin{array}{l}\text { Women with } \\
\text { migraine using } \\
\text { COCs vs. women } \\
\text { without migraine } \\
\text { not using COCs }\end{array}$ & $\begin{array}{l}\text { Women with } \\
\text { migraine not using } \\
\text { COCs vs. women } \\
\text { without migraine } \\
\text { not using COCs }\end{array}$ & $\begin{array}{l}\text { Women with } \\
\text { migraine using } \\
\text { COCs vs. women } \\
\text { with migraine } \\
\text { not using COCs }\end{array}$ & $\begin{array}{l}\text { Women without } \\
\text { migraine using } \\
\text { COCs vs. women } \\
\text { without migraine } \\
\text { not using COCs }\end{array}$ \\
\hline Collaborative Group [120] ${ }^{\mathrm{a}}$ & High dose COCs & & & $5.9 ; 2.9-12.2$ & $4.9 ; 2.9-8.3$ \\
\hline Tzourio [125] & $\begin{array}{l}\text { Progestogen only } \\
\text { High and low dose COCs }\end{array}$ & $13.9 ; 5.5-35.1$ & $3.7 ; 1.5-9.1$ & & $3.5 ; 1.5-8.3$ \\
\hline Schwartz [124] & Low dose COCs & & & $2.08 ; 1.19-3.65$ & $0.88 ; 0.44-1.76$ \\
\hline Chang [119] & High and low dose COCs & $16.9 ; 2.72-106$ & $2.27 ; 0.69-7.47$ & & $2.76 ; 1.01-7.55$ \\
\hline
\end{tabular}

OR odds ratio, $C I$ confidence interval, COCs combined oral contraceptives

${ }^{\mathrm{a}}$ Values represent relative risk and $95 \% \mathrm{CI}$

postulated to be safer than oral estrogen with respect to stroke risk because it involves no exposure to first-pass liver metabolism and no increase in clotting factors and inflammatory markers when delivered across the skin [131]. There are no trial data directly comparing stroke risk with varying types and doses of estrogen as existing clinical trials were based on single regimens of HRT. Data from available observational studies are conflicting since some of them indicate a similar stroke risk between subjects using high and low doses of estrogen while other studies show a dose-response association [132-134]. Clinical trial results show that the use of either estrogen plus progestin or estrogen alone (taken orally) increases stroke risk in post-menopausal women [134-136].

\section{Prescription of hormonal treatments to migraineurs}

Given the increased risk of VD in women with migraine and the demonstrated increased risk of stroke in women who use COCs, concern about their use in women with migraine has been raised and several guidelines report indications about prescription of COCs to migraineurs (Table 5) [137-140]. There are currently no studies that can be used to develop an evidence-based approach to the prescription of COCs to migraineurs. Physicians, when prescribing COCS, should take into account the type of migraine and the additional risk factors. Since MwA is not a definite risk factor for stroke, no particular restrictions are warranted in women suffering from this condition, especially in those with no comorbid risk factors. On the contrary, oral contraceptives should be discouraged in women suffering from MwA since they may lead to a further increase in the vascular risk. Their prescription should certainly be contraindicated in women with MA and other comorbid vascular risk factors or congenital or acquired thrombophilia. The additional risk factors for ischemic stroke in women with migraine using COCs are age $>35$ years, ischemic heart disease, or cardiac disease with embolic potential, diabetes mellitus, family history of arterial disease, hyperlipidemia, hypertension, obesity (body mass index >30), smoking, and systemic diseases associated with stroke, including sickle cell disease and connective tissue disorders [138]. As the risk of stroke also increases with age, COCs use is also considered inappropriate for women with any type of migraine over the age of 35 years; moreover, women who smoke should be advised to quit smoking before starting COCs. No specific tests need to be undertaken other than those routinely performed or indicated by the patient's history or the presence of specific symptoms [138]. In some instances, starting COCs may be associated with a change or worsening in migraine. To date, the question of whether this change amplifies the risk of stroke in women has not been formally addressed but, as already suggested [138], new onset of migraine aura, new persisting headache, increased headache frequency or intensity, development of unusual aura symptoms, prolonged aura may necessitate further evaluation or cessation of COCs. The World Health Organization (WHO) considered progesteroneonly contraceptives to be safer than COCs in subjects suffering from migraine [140], although migraine has not been considered when studying the safety, in terms of vascular risk, of those types of contraceptives. Intrauterine devices, particularly copper-bearing devices with respect to levonorgestrel-releasing devices are considered even safer than other possible hormonal contraceptive methods [140]. An awareness-raising strategy on prescription of COCs to migraineurs is needed, which should target gynecologists who are the specialists most likely to prescribe COCs. Indeed, gynecologists are often unskilled to diagnose migraine and unaware of the association between migraine and VD as of the implications of COCs use in migraineurs. 


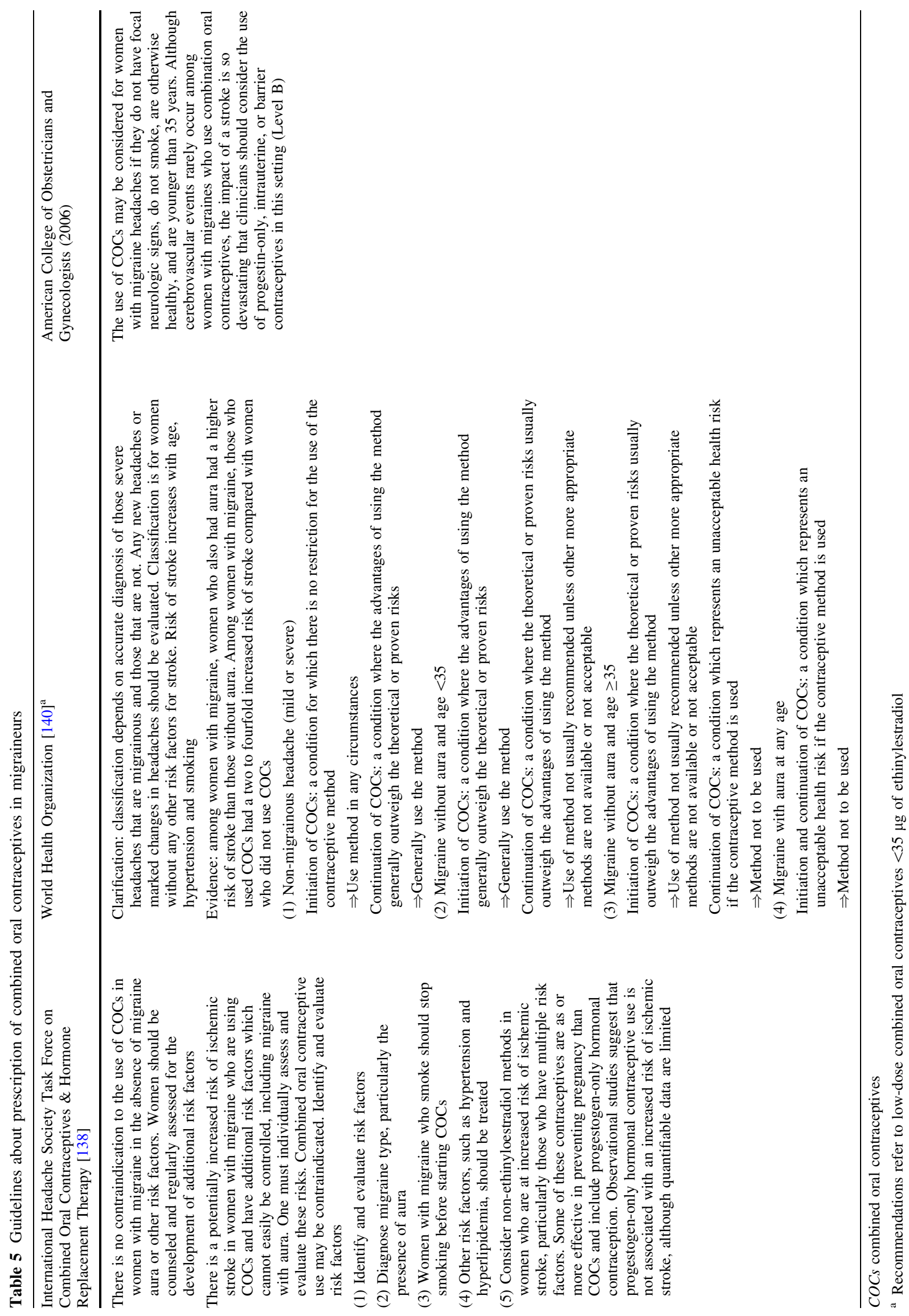


According to the International Headache Society Task Force on Combined Oral Contraceptives \& Hormone Replacement Therapy [138] there is no evidence that migraine is a risk factor for ischemic stroke in women over 45 years of age. There are insufficient data to support an increased risk of ischemic stroke in women with any type of migraine who are using HRT. Consequently, the usual indications and contraindications for HRT should be applied. New onset headache should be carefully evaluated for secondary causes. If aura starts for the first time, transient ischemic attack should be excluded. The dose and route of delivery of estrogen replacement should be assessed to provide the lowest effective dose necessary to control menopause symptoms. If aura does not resolve, withdrawal of estrogen and non-hormonal strategies should be considered.

\section{Conflict of interest None.}

Open Access This article is distributed under the terms of the Creative Commons Attribution License which permits any use, distribution, and reproduction in any medium, provided the original author(s) and the source are credited.

\section{References}

1. Lipton RB, Bigal ME, Diamond M, Freitag F, Reed ML, Stewart WF (2007) Migraine prevalence, disease burden, and the need for preventive therapy. Neurology 68:343-349

2. Stewart WF, Wood C, Reed ML, Roy J, Lipton RB (2008) Cumulative lifetime migraine incidence in women and men. Cephalalgia 28:1170-1178

3. Lipton RB, Bigal ME (2005) Migraine: epidemiology, impact, and risk factors for progression. Headache 45:S3-S13

4. Russell MB, Rasmussen BK, Fenger K, Olesen J (1996) Migraine without aura and migraine with aura are distinct clinical entities: a study of four hundred and eighty-four male and female migraineurs from the general population. Cephalalgia 16:239-245

5. Takele GM, Tekle HR, Martelletti P (2008) Prevalence and burden of primary headache in Akaki textile mill workers, Ethiopia. J Headache Pain 9:119-128

6. TeVelde E, Pearson P (2002) The variability of female reproductive aging. Hum Reprod Update 8:141-154

7. Granella F, Sances G, Pucci E, Nappi RE, Ghiotto N, Nappi G (2000) Migraine with aura and reproductive life events: a case control study. Cephalalgia 20:701-707

8. Wober C, Brannath W, Schmidt K, Kapitan M, Rudel E, Wessely P, Wober-Bingol C (2007) Prospective analysis of factors related to migraine attacks: the PAMINA study. Cephalalgia 27:304-314

9. Dzoljic E, Sipetic S, Vlajinac H, Marinkovic J, Brzakovic B, Pokrajac M, Kostic V (2002) Prevalence of menstrually related migraine and nonmigraine primary headache in female students of Belgrade University. Headache 42:185-193

10. Johannes CB, Linet MS, Stewart WF, Celentano DD, Lipton RB, Szklo M (1995) Relationship of headache to phase of the menstrual cycle among young women: a daily diary study. Neurology 45:1076-1082
11. MacGregor EA, Hackshaw A (2004) Prevalence of migraine on each day of the natural menstrual cycle. Neurology 63:351-353

12. Stewart WF, Lipton RB, Chee E, Sawyer J, Silberstein SD (2000) Menstrual cycle and headache in a population sample of migraineurs. Neurology 55:1517-1523

13. International Headache Society (2004) The international classification of headache disorders, 2nd edition. Cephalalgia 24:1-160

14. Cupini LM, Matteis M, Troisi E, Calabresi P, Bernardi G, Silvestrini M (1995) Sex-hormone-related events in migrainous females. A clinical comparative study between migraine with aura and migraine without aura. Cephalalgia 15:140-144

15. Granella F, Sances G, Zanferrari C, Costa A, Martignoni E, Manzoni GC (1993) Migraine without aura and reproductive life events: a clinical epidemiological study in 1300 women. Headache 33:385-389

16. MacGregor EA, Chia H, Vohrah RC, Wilkinson M(1990) Migraine and menstruation: a pilot study. Cephalalgia 10:305-310

17. Vetvik KG, MacGregor EA, Lundqvist C, Russell MB (2010) Self-reported menstrual migraine in the general population. J Headache Pain 11:87-92

18. MacGregor EA (2004) Oestrogen and attacks of migraine with and without aura. Lancet Neurol 3:354-361

19. MacGregor EA, Frith A, Ellis J, Aspinall L, Hackshaw A (2006) Incidence of migraine relative to menstrual cycle phases of rising and falling estrogen. Neurology 67:2154-2158

20. Couturier EG, Bomhof MA, Neven AK, van Duijn NP (2003) Menstrual migraine in a representative Dutch population sample: prevalence, disability and treatment. Cephalalgia 23:302-308

21. Dowson AJ, Kilminster SG, Salt R, Clark M, Bundy MJ (2005) Disability associated with headaches occurring inside and outside the menstrual period in those with migraine: a general practice study. Headache 45:274-282

22. Granella F, Sances G, Allais G, Nappi RE, Tirelli A, Benedetto C, Brundu B, Facchinetti F, Nappi G (2004) Characteristics of menstrual and nonmenstrual attacks in women with menstrually related migraine referred to headache centres. Cephalalgia 24:707-716

23. MacGregor E, Victor T, Hu X, Xiang Q, Puenpatom R, Chen W, Campbell J (2010) Characteristics of menstrual vsnonmenstrual migraine: a post hoc, within woman analysis of the usual-care phase of a nonrandomized menstrual migraine clinical trial. Headache 50:528-538

24. Pinkerman B, Holroyd K (2010) Menstrual and nonmenstrual migraines differ in women with menstrually-related migraine. Cephalalgia 30:1187-1194

25. Diamond ML, Cady RK, Mao L, Biondi DM, Finlayson G, Greenberg SJ, Wright P (2008) Characteristics of migraine attacks and responses to almotriptan treatment: a comparison of menstrually related and nonmenstrually related migraines. Headache 48:248-258

26. Facchinetti F, Neri I, Martignoni E, Fioroni L, Nappi G, Genazzani AR (1993) The association of menstrual migraine with the premenstrual syndrome. Cephalalgia 13:422-425

27. Martin VT, Wernke S, Mandell K, Ramadan N, Kao L, Bean J, Liu J, Zoma W, Rebar R (2006) Symptoms of premenstrual syndrome and their association with migraine headache. Headache 46:125-137

28. Aegidius K, Zwart JA, Hagen K, Stovner L (2009) The effect of pregnancy and parity on headache prevalence: the Head-HUNT study. Headache 49:851-859

29. Kvisvik EV, Stovner LJ, Helde G, Bovim G, Linde M (2011) Headache and migraine during pregnancy and puerperium: the MIGRA-study. J Headache Pain 12:443-451

30. Sances G, Granella F, Nappi RE, Fignon A, Ghiotto N, Polatti F, Nappi G (2003) Course of migraine during pregnancy and postpartum: a prospective study. Cephalalgia 23:197-205 
31. Melhado E, Maciel JA Jr, Guerreiro CA (2005) Headaches during pregnancy in women with a prior history of menstrual headaches. Arq Neuropsiquiatr 63:934-940

32. Marcus DA, Scharff L, Turk D (1999) Longitudinal prospective study of headache during pregnancy and postpartum. Headache 39:625-632

33. Estrevag JM, Zwart JA, Helde G, Johnsen HJ, Bovim G (2005) Headache and transient focal neurological symptoms during pregnancy, a prospective cohort. Acta Neurol Scand 111:233-237

34. Somerville BW (1972) A study of migraine in pregnancy. Neurology 22:824-828

35. Maggioni F, Alessi C, Maggino T, Zanchin G (1997) Headache during pregnancy. Cephalalgia 17:765-769

36. Bushnell CD, Jamison M, James AH (2009) Migraine during pregnancy linked to stroke and vascular diseases: US population based case-control study. BMJ 338:b664

37. Facchinetti F, Allais G, Nappi RE, D’Amico R, Marozio L, Bertozzi L, Ornati A, Benedetto C (2009) Migraine is a risk factor for hypertensive disorders in pregnancy: a prospective cohort study. Cephalalgia 29:286-292

38. Blair EM, Nelson KB (2011) Migraine and preterm birth. J Perinatol 31:434-439

39. Chen HM, Chen SF, Chen YH, Lin HC (2010) Increased risk of adverse pregnancy outcomes for women with migraines: a nationwide population-based study. Cephalalgia 30:433-438

40. Wang SJ, Fuh JL, Lu SR, Juang KD, Wang PH (2003) Migraine prevalence during menopausal transition. Headache 43:470-478

41. Freeman EW, Sammel MD, Lin H, Gracia CR, Kapoor S (2008) Symptoms in the menopausal transition: hormone and behavioral correlates. Obstet Gynecol 111:127-136

42. Neri I, Granella F, Nappi R, Manzoni GC, Facchinetti F, Genazzani AR (1993) Characteristics of headache at menopause: a clinico-epidemiologic study. Maturitas 17:31-37

43. Mattsson P (2003) Hormonal factors in migraine: a populationbased study of women aged 40 to 74 years. Headache 43:27-35

44. Sabia S, Fournier A, Mesrine S, Boutron-Ruault MC, ClavelChapelon F (2008) Risk factors for onset of menopausal symptoms: results from a large cohort study. Maturitas 60:108-121

45. Aegidius K, Zwart JA, Hagen K, Schei B, Stovner LJ (2006) Oral contraceptives and increased headache prevalence: the Head-HUNT study. Neurology 66:349-353

46. Mueller L (2000) Predictability of exogenous hormone effect in subgroups of migraineurs. Headache 40:189-193

47. Massiou H, MacGregor EA (2000) Evolution and treatment of migraine with oral contraceptives. Cephalalgia 20:170-174

48. Loder EW, Buse DC, Golub JR (2005) Headache as a side effect of combination estrogen-progestin oral contraceptives: a systematic review. Am J Obstet Gynecol 193:636-649

49. MacGregor EA, Hackshaw A (2002) Prevention of migraine in the pill-free week of combined oral contraceptives using natural oestrogen supplements. J Fam Plann Reprod Health Care 28:27-31

50. Sulak PJ, Scow RD, Preece C, Riggs MW, Kuehl TJ (2000) Hormone withdrawal symptoms in oral contraceptive users. Obstet Gynecol 95:261-266

51. Sulak P, Willis S, Kuehl T, Coffee A, Clark J (2007) Headaches and oral contraceptives: impact of eliminating the standard 7-day placebo interval. Headache 47:27-37

52. Edelman A, Gallo MF, Nichols MD, Jensen JT, Schulz KF, Grimes DA (2006) Continuous versus cyclic use of combined oral contraceptives for contraception: systematic Cochrane review of randomized controlled trials. Hum Reprod 21:573-578

53. LaGuardia KD, Fisher AC, Bainbridge JD, LoCoco JM, Friedman AJ (2005) Suppression of estrogen-withdrawal headache with extended transdermal contraception. Fertil Steril 83:1875-1877
54. De Leo V, Scolaro V, Musacchio MC, Di Sabatino A, Morgante G, Cianci A (2011) Combined oral contraceptives in women with menstrual migraine without aura. Fertil Steril 96:917-920

55. Curtis KM, Chrisman CE, Peterson HB (2002) Contraception for women in selected circumstances. Obstet Gynecol 99:1100-1102

56. Nappi RE, Sances G, Allais G, Terreno E, Benedetto C, Vaccaro V, Polatti F, Facchinetti F (2011) Effects of an estrogen-free, desogestrel-containing oral contraceptive in women with migraine with aura: a prospective diary-based pilot study. Contraception 83:223-228

57. Misakian AL, Langer RD, Bensenor IM, Cook NR, Manson JE, Buring JE, Rexrode KM (2003) Post-menopausal hormone therapy and migraine headache. J Womens Health (Larchmt) 12:1027-1036

58. Chinn MA (1968) Oestrogen therapy and migraine. Br Med J 2:699

59. Hodson J, Thompson J, al-Azzawi F (2000) Headache at menopause and in hormone replacement therapy users. Climacteric $3: 119-124$

60. Moorhead T, Hannaford P, Warskyj M (1997) Prevalence and characteristics associated with use of hormone replacement therapy in Britain. Br J Obstet Gynaecol 104:290-297

61. Warren MP, Kulak J Jr (1998) Is estrogen replacement indicated in perimenopausal women? Clin Obstet Gynecol 41:976-987

62. MacGregor A (1999) Effects of oral and transdermal estrogen replacement on migraine. Cephalalgia 19:124-125

63. Kaiser HJ, Meienberg O (1993) Deterioration of onset of migraine under oestrogen replacement therapy in the menopause. J Neurol Neurosurg Psychiatr 240:195-197

64. Martin VT (2004) Menstrual migraine: a review of prophylactic therapies. Curr Pain Headache Rep 8:229-237

65. Somerville BW (1972) The role of estradiol withdrawal in the etiology of menstrual migraine. Neurology 22:355-365

66. Amir BY, Yaacov B, Guy B, Gad P, Itzhak W, Gal I (2005) Headaches in women undergoing in vitro fertilization and embryo-transfer treatment. Headache 45:215-219

67. Sulak PJ, Kuehl TJ, Ortiz M, Shull BL (2002) Acceptance of altering the standard 21-day/7-day oral contraceptive regimen to delay menses and reduce hormone withdrawal symptoms. Am J Obstet Gynecol 186:1142-1149

68. Colson NJ, Lea RA, Quinlan S, MacMillan J, Griffiths LR (2004) The estrogen receptor 1 G594A polymorphism is associated with migraine susceptibility in two independent case/ control groups. Neurogenetics 5:129-133

69. Colson NJ, Lea RA, Quinlan S, MacMillan J, Griffiths LR (2005) Investigation of hormone receptor genes in migraine. Neurogenetics 6:17-23

70. Aloisi A (2003) Gonadal hormones and sex differences in pain reactivity. Clin J Pain 19:168-174

71. Stoffel-Wagner B (1993) Neurosteroid biosynthesis in the human brain and its clinical implications. Ann NY Acad Sci 1007:64-78

72. Facchinetti F, Martignoni E, Fioroni L, Sances G, Genazzani AR (1990) Opioid control of the hypothalamus-pituitary-adrenal axis cyclically fails in menstrual migraine. Cephalalgia 10:51-56

73. Horrobin D (1977) Prostaglandins and migraine. Headache 16:113-116

74. Carlson LA, Ekelund LG, Orö L (1968) Clinical and metabolic effects of different doses of prostaglandin E1 in man. Prostaglandin and related factors. Acta Med Scand 183:423-430

75. Martin VT, Behbehani M (2006) Ovarian hormones and migraine headache: understanding mechanisms and pathogenesis-part I. Headache 46:3-23

76. Akcali D, Sayin A, Sara Y, Bolay H (2010) Does single cortical spreading depression elicit pain behaviour in freely moving rats? Cephalalgia 30:1195-1206 
77. Marrannes R, Willems R, De Prins E, Wauquier A (1988) Evidence for a role of the N-methyl-D-aspartate (NMDA) receptor in cortical spreading depression in the rat. Brain Res 457:226-240

78. Muneyvirci-Delale O, Nacharaju VL, Altura BM, Altura BT (1998) Sex steroid hormones modulate serum ionized magnesium and calcium levels throughout the menstrual cycle in women. Fertil Steril 69:958-962

79. Fioroni L, Martignoni E, Facchinetti F (1995) Changes of neuroendocrine axes in patients with menstrual migraine. Cephalalgia 15:297-300

80. Facchinetti F, Sgarbi L, Piccinini F (2000) Hypothalamic resetting at puberty and the sexual dimorphism of migraine. Funct Neurol 15:137-142

81. Brandes JL (2006) The influence of estrogen on migraine: a systematic review. JAMA 295:1824-1830

82. Chen Z, Yuhanna IS, Galcheva-Gargova Z, Karas RH, Mendelsohn ME, Shaul PW (1999) Estrogen receptor alpha mediates the nongenomic activation of endothelial nitric oxide synthase by estrogen. J Clin Invest 103:401-406

83. Sarchielli P, Tognoloni M, Russo S, Vulcano MR, Feleppa M, Malà M, Sartori M, Gallai V (1996) Variations in the platelet arginine/ nitric oxide pathway during the ovarian cycle in females affected by menstrual migraine. Cephalalgia 16:468-475

84. Edwards HE, Burnham WM, Mendonca A, Bowlby DA, MacLusky NJ (1999) Steroid hormones affect limbic after discharge thresholds and kindling rates in adult female rats. Brain Res 838:136-150

85. Hattemer K, Knake S, Reis J, Oertel WH, Rosenow F, Hamer HM (2006) Cyclical excitability of the motor cortex in patients with catamenial epilepsy: a transcranial magnetic stimulation study. Seizure 15:653-657

86. Bousser MG, Welch KM (2005) Relation between migraine and stroke. Lancet Neurol 4:533-542

87. Carolei A, Marini C, De Matteis G (1996) History of migraine and risk of cerebral ischaemia in young adults. The Italian National Research Council Study Group on stroke in the young. Lancet 347:1503-1506

88. Sacco S, Olivieri L, Bastianello S, Carolei A (2006) Comorbid neuropathologies in migraine. J Headache Pain 7:222-230

89. Sacco S, Cerone D, Carolei A (2008) Comorbid neuropathologies in migraine: an update on cerebrovascular and cardiovascular aspects. J Headache Pain 9:237-248

90. Sacco S, Ricci S, Carolei A (2012) Vascular vulnerability in migraineurs (in press)

91. Schürks M, Rist PM, Bigal ME, Buring JE, Lipton RB, Kurth T (2009) Migraine and cardiovascular disease: systematic review and meta-analysis. BMJ 339:b3914

92. Kurth T, Gaziano JM, Cook NR, Logroscino G, Diener HC, Buring JE (2006) Migraine and risk of cardiovascular disease in women. JAMA 296:283-291

93. Kurth T, Gaziano JM, Cook NR, Bubes V, Logroscino G, Diener HC, Buring JE (2007) Migraine and risk of cardiovascular disease in men. Arch Intern Med 167:795-801

94. Bigal ME, Kurth T, Santanello N, Buse D, Golden W, Robbins M, Lipton RB (2010) Migraine and cardiovascular disease: a population-based study. Neurology 74:628-635

95. Gudmundsson LS, Scher AI, Aspelund T, Eliasson JH, Johannsson M, Thorgeirsson G, Launer L, Gudnason V (2010) Migraine with aura and risk of cardiovascular and all cause mortality in men and women: prospective cohort study. BMJ 341:c3966

96. Schürks M, Rist PM, Shapiro RE, Kurth T (2011) Migraine and mortality: a systematic review and meta-analysis. Cephalalgia 31:1301-1314

97. Bushnell CD (2005) Oestrogen and stroke in women: assessment of risk. Lancet Neurol 4:743-751
98. Miller VM, Duckles SP (2008) Vascular actions of estrogens: functional implications. Pharmacol Rev 60:210-241

99. Skafar DF, Xu R, Morales J, Ram J, Sowers JR (1997) Female sex hormones and cardiovascular disease in women. J Clin Endocrinol Metab 82:3913-3918

100. Farhat MY (1996) The vascular protective effects of estrogen. FASEB J 10:615-624

101. Moragham T, Antoniucci DM, Grenert JP, Sieck GC, Johnson C, Miller VM, Fitzpatrick LA (1996) Differential response in cell proliferation to beta estradiol in coronary arterial vascular smooth muscle cells obtained form mature female vs. male animals. Endocrinology 137:5174-5177

102. Oparil S, Levin RL, Chen YF (1996) Sex hormones and the vasculature. In: Sowers JR (ed) Endocrinology of the vasculature. Humana Press, Totowa, pp 225-238

103. Vargas R, Wroblewska B, Rego A, Hatch J, Ramwell PW (1993) Oestradiol inhibits smooth muscle cell proliferation of pig coronary artery. Br J Pharmacol 109:612-617

104. Hayashi T, Fukuto JM, Ignarro LJ, Chaudhuri G (1992) Basal release of nitric oxide from aortic rings is greater in female rabbits than in male rabbits: implications for atherosclerosis. Proc Natl Acad Sci USA 89:11259-11263

105. Weiner CP, Lizasoain I, Baylis SA, Knowles RG, Charles IG, Moncada S (1994) Induction of calcium-dependent nitric oxide syntheses by sex hormones. Proc Natl Acad Sci USA 91:5212-5216

106. Hayashi T (1995) Estrogen increased endothelial nitric oxide by a receptor-mediated system. Biochem Biophys Res Commun 214:847-855

107. Hishikawa K (1995) Up-regulation of nitric oxide synthase by estradiol in human aortic endothelial cells. FEBS Lett 360:291-293

108. Losordo DW, Kearney M, Kim EA, Jekanowski J, Isner JM (1994) Variable expression of the estrogen receptor in normal and atherosclerotic coronary arteries of premenopausal women. Circulation 89:1501-1510

109. Lin AL, Gonzalez R, Carey KD, Shain SA (1986) Estradiol-17 affects E2 receptor distribution and elevates $\mathrm{P}$ receptor content in baboon aorta. Arteriosclerosis 6:495-504

110. Miller VM, Vanhoutte PM (1991) Progesterone and modulation of endothelium-dependent responses in canine coronary arteries. Am J Physiol 261:R1022-R1027

111. Hanke H, Hanke S, Bruck B, Brehme U, Gugel N, Finking G, Mück AO, Schmahl FW, Hombach V, Haasis R (1996) Inhibition of the protective effect of estrogen by progesterone in experimental atherosclerosis. Atherosclerosis 121:129-138

112. Hanke H, Hanke S, Finking G, Muhic-Lohrer A, Mück AO, Schmahl FW, Haasis R, Hombach V (1996) Different effects of estrogen and progesterone on experimental atherosclerosis in female vs. male rabbits. Quantification of cellular proliferation by bromodeoxyuridine. Circulation 94:175-181

113. Iruela-Arispe ML, Porter P, Bornstein P, Sage EH (1996) Thrombospondin-1, an inhibitor of angiogenesis, is regulated by progestins, in the human endometrium. J Clin Invest 97:403-412

114. Jiang CW, Sarrel PM, Lindsay DC, Poole-Wilson PA, Collins P (1992) Progesterone induces endothelium-independent relaxation of rabbit coronary artery in vitro. Eur J Pharmacol 211:163-167

115. Raman BB, Standley PR, Rajkumar V, Ram JL, Sowers JR (1995) Effects of estradiol and progesterone on platelet calcium responses. Am J Hypertens 8:197-200

116. Kemmeren JM, Algra A, Grobbee DE (2001) Third generation oral contraceptives and risk of venous thrombosis: meta-analysis. BMJ 323:131-134

117. Baillargeon JP, McClish DK, Essah PA, Nestler JE (2005) Association between the current use of low-dose oral contraceptives and cardiovascular arterial disease: a meta-analysis. J Clin Endocrinol Metab 90:3863-3870 
118. Petitti DB (2003) Clinical practice. Combination estrogen-progestin oral contraceptives. N Engl J Med 349:1443-1450

119. Chang CL, Donaghy M, Poulter N (1999) Migraine and stroke in young women: case-control study. The World Health Organisation Collaborative Study of cardiovascular disease and steroid hormone contraception. BMJ 318:13-18

120. Collaborative Group for the Study of Stroke in Young Women (1975) Oral contraceptives and stroke in young women. JAMA 231:718-722

121. Lidegaard $\varnothing$ (1993) Oral contraception and risk of a cerebral thromboembolic attack: results of a case-control study. BMJ 306:956-963

122. Lidegaard Ø (1995) Oral contraceptives, pregnancy and the risk of cerebral thromboembolism: the influence of diabetes, hypertension, migraine and previous thrombotic disease. $\mathrm{Br} \mathrm{J}$ Obstet Gynaecol 102:153-159

123. MacClellan LR, Giles W, Cole J, Wozniak M, Stern B, Mitchell BD, Kittner SJ (2007) Probable migraine with visual aura and risk of ischemic stroke: the stroke prevention in young women study. Stroke 38:2438-2445

124. Schwartz SM, Petitti DB, Siscovick DS, Longstreth WT Jr, Sidney S, Raghunathan TE, Quesenberry CP Jr, Kelaghan J (1998) Stroke and use of low-dose oral contraceptives in young women: a pooled analysis of two US studies. Stroke 29:2277-2284

125. Tzourio $\mathrm{C}$, Tehindrazanarivelo A, Iglésias S, Alpérovitch A, Chedru F, d'Anglejan-Chatillon J, Bousser MG (1995) Casecontrol study of migraine and risk of ischaemic stroke in young women. BMJ 310:830-833

126. Curtis KM, Mohllajee AP, Peterson HB (2006) Use of combined oral contraceptives among women with migraine and nonmigrainous headaches: a systematic review. Contraception 73:189-194

127. Hersh AL, Stefanick ML, Stafford RS (2004) National use of postmenopausal hormone therapy: annual trends and response to recent evidence. JAMA 291:47-53

128. Hulley S, Grady D, Bush T, Furberg C, Herrington D, Riggs B, Vittinghoff E (1998) Randomized trial of estrogen plus progestin for secondary prevention of coronary heart disease in postmenopausal women. JAMA 280:605-613

129. Viscoli CM, Brass LM, Kernan WN, Sarrel PM, Suissa S, Horwitz RI (2001) A clinical trial of estrogen-replacement therapy after ischemic stroke. N Engl J Med 345:1243-1249

130. Evenson KR, Wilcox S, Pettinger M, Brunner R, King AC, McTiernan A, Women's Health Initiative Observational Cohort Study (2002) Vigorous leisure activity through women's adult life: the women's health initiative observational cohort study. Am J Epidemiol 156:945-953

131. Hemelaar M, van der Mooren M, Rad M, Kluft C, Kenemans P (2008) Effects of non-oral postmenopausal hormone therapy on markers of cardiovascular risk: a systematic review. Fertil Steril 90:642-672

132. Arana A, Varas C, Gonzalez-Perez A, Gutierrez L, Bjerrum L, Garcia Rodriguez LA (2006) Hormone therapy and cerebrovascular events: a population-based nested case-control study. Menopause 13:730-736

133. Grodstein F, Manson JE, Colditz GA, Willett WC, Speizer FE, Stampfer MJ (2000) A prospective, observational study of postmenopausal hormone therapy and primary prevention of cardiovascular disease. Ann Intern Med 133:922-941

134. Renoux C, Dell'Aniello S, Garbe E, Suissa S (2010) Transdermal and oral hormone replacement therapy and the risk of stroke: a nested case-control study. BMJ 340:c2519

135. Hendrix SL, Wassertheil-Smoller S, Johnson KC, Howard BV, Kooperberg C, Rossouw JE, Trevisan M, Aragaki A, Baird AE, Bray PF, Buring JE, Criqui MH, Herrington D, Lynch JK, Rapp SR, Torner J (2006) Effects of conjugated equine estrogen on stroke in the women's health initiative. Circulation 113:2425-2434

136. Wassertheil-Smoller S, Hendrix SL, Limacher M, Heiss G, Kooperberg C, Baird A, Kotchen T, Curb JD, Black H, Rossouw JE, Aragaki A, Safford M, Stein E, Laowattana S, Mysiw WJ (2003) Effect of estrogen plus progestin on stroke in postmenopausal women. The women's health initiative: a randomized trial. JAMA 289:2673-2684

137. ACOG Committee on Practice Bulletins-Gynecology (2006) ACOG practice bulletin. No 73: use of hormonal contraception in women with coexisting medical conditions. Obstet Gynecol 107:1453-1472

138. Bousser MG, Conard J, Kittner S, de Lignières B, MacGregor EA, Massiou H, Silberstein SD, Tzourio C (2000) Recommendations on the risk of ischaemic stroke associated with use of combined oral contraceptives and hormone replacement therapy in women with migraine. The International Headache Society Task Force on combined oral contraceptives \& hormone replacement therapy. Cephalalgia 20:155-156

139. Faculty of Sexual and Reproductive Health Care (2009) UK medical eligibility criteria for contraceptive use (UKMEC 2009). Royal College of Obstetricians and Gynaecologists

140. World Health Organization (2004) Medical eligibility criteria for contraceptive use, 3rd edn. World Health Organization, Geneva 